International Journal of Stem Cell Research and Transplantation (IJST)

ISSN: 2328-3548

\title{
Property Of Human Dental Pulp Stem Cells And Peripheral Blood Hematopoietic Stem Cells That Dif- ferentiated Both Group To Cardiac Cells
}

Research Article

Jabari $\mathrm{F}^{1^{*}}$, Mohammadnejad $\mathrm{J}^{2}$, Yavari $\mathrm{K}^{3}$

${ }^{1}$ Faculty of New Sciences and Technologies, University of Tehran, Tehran, Iran.

${ }^{2}$ Professor assistance, Department of Life Science Engineering, Faculty of New Sciences and Technologies, University of Tehran, Tehran, Iran

${ }^{3}$ Professor assistance, Biotechnology lab, Nuclear Science and Technology Research institute, (NSTRI), atomic nuclear energy organization, Tehran, Iran.

\section{Abstract}

Dental pulp is the soft live tissue inside a tooth. Dental pulp contains stem cells, known as Dental Pulp Stem Cells. The finest Dental Pulp Stem Cells are found in a baby teeth or milk teeth. The stem cells from the milk teeth are 'mesenchymal' type of cells. cells that have the ability to generate a wide variety of cell types like chondrocytes, osteoblasts and adipocytes. To isolate high-quality human dental pulp stem cells from accessible resources is an important goal for stem-cell research. In this study we found that exfoliated human deciduous tooth contains multipotent stem cells, they identified to be a population of highly proliferative, clonogenic cells. Hematopoietic stem cells (HSCs) are the blood cells that give rise to all the other blood cells. HSCs are found in the bone marrow of adults, with large quantities in the pelvis, femur, and they are also found in umbilical cord blood and, in small numbers, in blood. In this study we differentiated stem cells that isolated from human dental pulp and peripheral blood to cardiac cells. The isolation process for dental pulp stem cells would take place in 2 different methods: The enzymatic digestion method and, the second method is a subsidiary one. For isolating the stem cells from peripheral blood we use ficoll method. Flow cytometery analyzes showed that dental pulp stem cells are mesanchymal and peripheral blood cells are hematopoietic stem cells. Bothe group of stem cells can differentiation to cardiac cells. Dental pulp stem cells are mesanchymal cells and peripheral blood cells are hematopoietic cells. For differentiation the cells to cardiomyocite we used 5-azacitidin and exitocin. After differentiation stem cells to cardiac cells, dental pulp stem cells and peripheral blood stem cells morphology was changed, before differentiation to cardiac cells, both group were elongated and after differentiated to cardiomyocit they have central typical nuclear and were stratified, they expanded cytoplasmic papillae .

Key Words: Dental Pulp Stem Cell; Supernumerary Tooth; Differentiation; Adiposite; Osteoblast.

\section{*Corresponding Author:}

Farzaneh Jabari,

Faculty of New Sciences and Technologies, University of Tehran,

Tehran, Iran.

E-mail: jabarifarzane@yahoo.com

Received: October 19, 2013

Accepted: October 30, 2013

Published: October 31, 2013

Citation: Jabari F, Mohammadnejad J, Yavari K. (2013). Property of Human Dental Pulp Stem Cells and Peripheral Blood Hematopoietic Stem Cells That Differentiated Both Group to Cardiac Cells, Int J Stem Cell Res Transplant, 01(06), 37-39. doi: http:/ /dx.doi. org/10.19070/2328-3548-130007

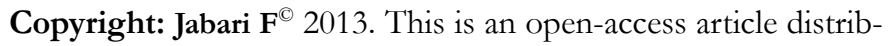
uted under the terms of the Creative Commons Attribution License, which permits unrestricted use, distribution and reproduction in any medium, provided the original author and source are credited.

\section{Introduction}

Among different source for stem cells, less attention has been paid to the human dental pulp. Human dental pulps are the best and new source for stem cells, and have potential to different to all kinds of cells. So the aim of this study was to evaluate the pulp ability for produce stem cells for clinical application.

\section{Objectives}

In this study we tried to isolated stem cells from human primary dental pulp and peripheral blood. Peripheral blood mononucleated cells consist of hematopoietic stem cells (HSCs) and mesenchymal stem cells (MSCs). To date there is no well-defined isolation or characterisation protocol of stem cells from human adult peripheral blood mononucleated cells. Our aim in this study was to isolate and characterize mononucleated cells from human peripheral blood. Peripheral blood mononucleated cells were isolated using the Ficoll-Paque density gradient separation method and cultured in complete medium We want to show that both group of stem cells are the best Candida to clinical treatment, dental pulp stem cells can differentiated to all kind of cells like cardiac cells and are used to treatment disease.

\section{Methods}

Primary teeth falling and their replacement with permanent ones, is physiologically an active process which involves the genesis of permanent teeth and the absorption of primary teeth roots simultaneously. The normal incisor pulp from 8-12 years old children primary teeth is isolated and its stem cells are cultured after purification. The falling primary dental like wisdom teeth have a soft 
tissue in their proximal part which contains stem cells. [1,2] The isolation process would take place in 2 different methods: The enzymatic digestion method: in this method the tissue sample is placed in $3 \mathrm{mg} / \mathrm{ml}$ type I collagenase, $4 \mathrm{mg} / \mathrm{ml}$ dyspase, For“ 30 60 "minutes at $37^{\circ} \mathrm{C}$ after cutting into small slices. The resulting cell suspension is then passed through a 0.2 micrometer filter and cultured with 20\% Fetal Bovine Serum (FBS) supplemented with $100 \mu \mathrm{mol}$ of ascorbic acid 2-phosphate and $100 \mathrm{unit} / \mathrm{ml}$ penicillin in a $\mathrm{CO}_{2}$ cell culture incubator. These cells are called human dental pulp cells/digestion (HDPC-d). The second method is a subsidiary one, pulp tissue cut into small piece and put in 6-wall plate then we added all the previous method materials without dyspase and collagenas, plate were in incubator, after 40 day stem cells separated from pulp and we passaged them to flask. $[3,4,5,6]$ For isolating the stem cells from peripheral blood we use ficoll method, Three milliliters of Ficoll-Paque PREMIUM (Amersham tube. An equal volume of phosphate-buffered saline Biosciences, Uppsala, Sweden) were placed into a $15 \mathrm{ml}$ centrifuge (Gibco, Carlsbad, CA) was added into the vacuum PB collection tubes. The diluted mixture of specimen was slowly layered on top of the Ficoll-Paque PREMIUM. The centrifuge tube was then centrifuged for $40 \mathrm{~min}$ at $2000 \mathrm{rpm}$. The mononuclear cells were extracted and transferred into a new $15 \mathrm{ml}$ centrifuge tube. Cells were washed with Dulbecco's modified Eagle's low glucose (DMEM) (Gibco) with 1:1 dilution and underwent centrifugation at 1,200 rpm for15 min. The supernatant was then discarded. Cell pellet formed at the bottom were resuspended using $1 \mathrm{ml}$ of $37^{\circ} \mathrm{c}$ fetal bovine serum (FBS). The mixture of mononuclear Cells were then cultured in cell culture medium, which consisted of DMEM, 20\% FBS, peripherals blood cells derived HSCs were characterized using light microscopy to determine cell morphology. It is hypothesized that HSCs isolated from the blood of normal individuals share the same characteristics and ability to differentiate along cardiac cells $[7,8,9,10,11]$.for differentiation cells to cardiac cells we use 5 -azasitidin and exitocin $\left(1 / 10^{3} \mathrm{mM}\right)$. Cells were in 6-wall plate and we added DMEM, exitocine, 5 -azasitidin then put the plate in incubator for 21 day $[12,13]$

In order to induce cardio-differentiation, a number of 10000 cells were cultured in $35 \mathrm{ml}$ dishes with DMEM (Dulbecco's Modified Eagle's Medium)-LG supplemented by 15\% FBS (Fetal Bovine Serum), and after reaching an approximately $70 \%$ confluency, the cardio-differentiation is induced in these cells by treating them using Exitosin for a 4-week period. $[14,15,16]$ to confirm that dental pulp are mesanchymal stem cells and peripheral blood cells are hematopoietic, flow cytometery analyzes was don $[17,18,19]$.

\section{Results}

These findings confirm that, there is similarity between pluripotency genes expression in human dental pulp stem cell, and embryonic stem cells, so they can be categorized as pluripotent cells. One of the most interesting applications of pulp mesenchymal stem cells is Parkinson treatment. Parkinson is a nerve cell regeneration disorder which causes gradual death of Dopaminergic neurons and subsequently a decline in brain dopamine level. Dental pulp contains ex vivo-expandable cells called dental pulp stem cells (DPSCs), with the capacity to differentiate into multiple cell lineages. Dental pulp stem cells growth faster than peripheral blood cells and can be survive in culture medium without FBS but peripheral stem cells died in this medium. The colony numbers of dental pulp stem cells are much than peripheral blood stem cells, dental pulp stem cells are elongated and acerate but peripheral blood cells are spherical, differentiation rate for dental pulp was higher than peripheral blood cells, After providing the evidence to isolate stem/progenitor cells out of the dental pulp, proliferation studies have been described in various reports and exhibit a high proliferation rate dental pulp stem cells differentiated to cardiac cells in 21 day but the peripheral cells differentiated in 35 day. Dental pulp cells are mesanchymal stem cells because they expression CD166, and don't expression, CD38, CD34 markers. Peripherals cells expression CD34, CD38 high. Dental pulp cells and peripheral blood cells have the ability to differentiate into all kind of cells. Circulating blood is known to contain stem cells that can completely restore hematopoietic after ablation of the bone marrow. Whether such stem cells circulate in the blood is unsettled. MSCs are spindle-shaped with irregular processes. Cells treated with Exytocin and 5-azacytidin connected with adjoining cells to form myotube-like structures. These results indicate that stem cells, can differentiate into cardiomyocytes in vitro by treatment with Exytocin and 5-azacytidin, and can be considered as a source of cells for cellular cardiomyoplasty. The differentiation of MSCs into cells that expressed cardiac specific genes such as $\alpha 3$-actinin, beta - myosin heavy chain ( $\beta$-MHC).

\section{Conclusion}

Stem cells in the isolated mononucleotide cells were characterized using a multidisciplinary approach which was based on the expression of stem cell markers, morphology and the capacity to self-renew or proliferate and differentiate into specialized cells. mononucleated cells in suspension were positive for HSC markers. The isolated adherent and suspension mononucleated cells were able to maintain their stem cell properties during in-vitro culture by retaining their capacity to proliferate. Mesenchymal stem cells (MSCs) and haematopoietic stem cells (HSCs) are adult stem cells present in peripheral blood. MSCs are generally defined as self-renewable, multipotent progenitor cells with the ability to differentiate into several mesenchymal lineages including bone, cartilage, adipose and muscle tissues. In addition, MSCs have also demonstrated the potential to transdifferentiate into other types of tissues such as hepatic, renal, cardiac and neuronal tissues, thus indicating the cells pluripotency. HSCs are defined by their ability to repopulate all of the haematopoietic lineages in vivo and sustain the production of these cells for the lifespan of the individual. HSCs have been or are being used for the restoration of lymphohaematopoietic function after myeloablative, near myeloablative or non-myeloablative treatment. Our main objectives for this study were the isolation, culture and molecular characterisation of mononucleated cells from human peripheral blood and dental pulp stem cells. Dental pulp cells have the high growth rate than peripherals blood cells. Both of them are able to differentiation to cardiac cells but dental pulp stem cells differentiated faster than peripheral blood stem cells.

\section{Acknowledgments}

The authors acknowledge Sareh Abolhasani for technical support. This study was supported by Biotechnology lab, Nuclear Science and Technology Research institute, Tehran, Iran (NSTRI).

\section{Conflict of Interest}


The authors have no conflicting financial interest

\section{References}

[1]. Gronthos S, Brahim J, Li W, Fisher LW, Cherman N, Boyde A. Stem cell properties of human dental pulp stem cells. J Dent Res 2002; 81: 531-535.

[2]. Sloan AJ, Smith AJ. Stem cells and the dental pulp: potential roles in dentine regeneration and repair. Oral Dis 2007; 13: 151-7.

[3]. Lainv G, GraZiano A, d'Aquino R, Pirozzi G, Lanza V, Valiantes S. An approachable human adult stem cell source for hard tissue engineering. J cell physical 2006; 206: 693-701.

[4]. Jo YY, Lee HJ, Kook SY, Choung HW, Park JY, Chung JH. Isolation and characterization of postnatal stem cells from human dental tissues. Tissue Eng 2007;13:767-73.

[5]. Ruch JV. Odontoblanst commitment and differentiation Biochem cell Bial 1998; 76: 923-938.

[6]. Pandit A, Ashar R, Feldman D. The effect of TGF-beta delivered through a collagen scaffold on wound healing. 1999; 2: 89-100.

[7]. Novakovic G, Freed LE. Culture of organized cell communities. Adv Drug Delivery 1998; 33: 15-30.

[8]. Alhadlaq A, Mao JJ. Mesenchymal stem cells: Isolation and therapeutics. Stem Cells Dev 2004;13:436-448.

[9]. Kent DG, Copley MR, Benz C. Prospective isolation and molecular characterization of hematopoietic stem cells with durable self-renewal potential. Blood 2009;113:6342-6350.
[10]. Wognum W, Eaves AC, Thomas TE. Identification and isolation of hematopoietic stem cells. Arch Med Res 2003;34:461-475.

[11]. Shahrul ZA, Intan ZA, Sahidan S, Nor Muhammad M, Rohaya W, Zaidah ZA. Stem cells in blood development. Sains Malaysiana 2005;34:21-26.

[12]. Huber I, Itzhaki I, Caspi O, Arbel G, Tzukerman M, Gepstein A. Identification and selection of cardiomyocytes during human embryonic stem cell differentiation. FASEB J. 2007; 21: 2551-2563

[13]. Toma C, Pittenger F, Cahill S, Byrne BJ, Kessler D. Human mesenchymal stem cells differentiate to a cardiomyocyte phenotype in the adult murine heart. Circulation 2002; 105: 93-98.

[14]. Minguell JJ, Conget P, Erices A. Biology and clinical utilization of mesenchymal progenitor cells. Braz J Med Biol Res 2000; 33: 881-887.

[15]. Rangappa S, Reddy VG, Bongso A, Lee EH, Sim E. Transformation of the adult human mesenchymal stem cells into cardiomyocyte- like cells in vivo. Cardiovasc Eng: An International Journal 2002; 2: 7-14.

[16]. Hatami L, Valojerdi R, Mowla SJ. Effects of oxytocin on cardiomyocyte differentiation from mouse embryonic stem cells. Int J Cardiol 2007; 117: 80-89.

[17]. Lainv G, GraZiano A, d'Aquino R, Pirozzi G, Lanza V, Valiantes S. An approachable human adult stem cell source for hard tissue engineering, $\mathrm{J}$ cell physical 2006; 206: 693-701.

[18]. Kerkis I, Kerkis A, Dozortsev D, Stukart- Parsons GC, A I. Isolation and characterizations of a population of immature dental pulp stem cells expressing Oct -4 and other embryonic stem cells markers.cells tissues organs,2006; 184: 105-116.

[19]. Butter WT, Ritchie HH, Bronkers AL. Extracellular matrix proteins of dentine. Ciba Found Symp, 1997; 205: 107-115. 